\title{
EL INDULTO EN UN ESTADO CONSTITUCIONAL \\ DE DERECHO: ¿̨CORRECCIÓN, COMPASIÓN O \\ NEGOCIACIÓN? EN RELACIÓN A LA DECISIÓN \\ DE LA CORTE INTERAMERICANA DE \\ DERECHOS HUMANOS SOBRE EL INDULTO DEL EXPRESIDENTE DE PERÚ, ALBERTO FUJIMORI \\ O INDULTO EM UM ESTADO CONSTITUCIONAL DE DIREITO:
}

EM RELAÇÃO À DECISÃO DA CORTE INTERAMERICANA DE DIREITOS HUMANOS SOBRE O INDULTO DO EX-PRESIDENTE DO PERU, ALBERTO FUJIMORI

PARDON IN A CONSTITUTIONAL STATE OF LAW:

THE DECISION OF THE INTER-AMERICAN COURT OF HUMAN RIGHTS TO PARDON THE FORMER PRESIDENT OF PERU, ALBERTO FUJIMORI

Licença CC BY:

Artigo distribuído sob

os termos Creative

Commons, permite uso

e distribuição irrestrita

em qualquer meio desde

que $o$ autor credite a

fonte original.

\section{Ana Calderón Sumarriva ${ }^{1}$}

\section{(c) (i)}

\section{INTRODUCCIÓN DE LA PROBLEMÁTICA}

En abril de 2009 la Sala Penal Especial de la Corte Suprema del Perú condenó al expresidente Alberto Fujimori Fujimori a veinticinco años de pena privativa de libertad tras determinar que fue autor mediato de los delitos de homicidio calificado en agravio de quince personas en el caso Barrios Altos y otras diez en el caso La Cantuta, lesiones graves en agravio de cuatro víctimas del caso Barrios Altos, y secuestro agravado en agravio de un periodista. La Sala otorgó a todos estos delitos el carácter de lesa humanidad. Posteriormente, dicha sentencia fue confirmada por la Sala Penal Permanente de la Corte Suprema en diciembre de 2009.²

\footnotetext{
$1 \quad$ Doctora en Derecho por la Universidad Nacional de Rosario - UNR (Argentina). Magíster en Derecho Procesal por la Universidad Nacional de Rosario (Argentina). Maestro en Derecho Constitucional por la Universidad Nacional Federico Villarreal (Perú). Postitulada en Derecho Penal y Derecho Procesal Penal por la Pontificia Universidad Católica del Perú. Candidata a Doctor en Derecho en la Pontificia Universidad Católica del Perú. Abogada por la Universidad de San Martín de Porres. Docente en Derecho Penal y Derecho Procesal Penal en la Escuela de Postgrado de la Universidad Nacional Federico Villarreal.

2 "Con ello no se hace sino coincidir, a partir del cúmulo de pruebas ya analizadas, con las decisiones de la CIDH y el Tribunal Constitucional que, igualmente, calificaron estos actos de crímenes contra la humanidad según el Derecho Internacional Penal." (Sentencia de la Sala Penal Especial de la Corte Suprema del Perú de fecha 7 de abril de 2009, ultima parte del fundamento jurídico 717).
} 
Entre los años 2010 y 2018, un tema capturó la atención de la opinión pública: la posibilidad de indultar al expresidente Alberto Fujimori considerando su edad avanzada y las enfermedades que pudiera padecer. En el gobierno de Ollanta Humala, a mediados del año 2013, se le denegó el indulto sobre la base de los siguientes fundamentos: "no tiene una enfermedad terminal, no tiene un trastorno mental incurable, no tiene una enfermedad incurable ni degenerativa y las instalaciones (penitenciarias) tampoco coadyuvan en su perjuicio".

El 24 de diciembre de 2017, mediante Resolución Suprema N²81-2017-JUS se indultó por razones humanitarias al expresidente Alberto Fujimori cuando este tenía 79 años de edad y había cumplido diez años, diez meses y dos días de prisión. Entre los fundamentos más importantes que sustentaron la aludida resolución encontramos los siguientes:

"Que, en el presente caso, la gravedad de la enfermedad se configura como un argumento en el que se justifica la culminación de la ejecución penal que conlleva la gracia, sin sacrificar los fines de la pena constitucionalmente reconocidos, toda vez que se trata de un caso excepcional de una persona con enfermedad no terminal grave, lo que determina que la continuidad de la persecución penal pierda sentido, sin que ello afecte el ejercicio de las demás acciones orientadas a la restitución del perjuicio ocasionado;

Que, asimismo, la Comisión de Gracias Presidenciales ha determinado en el Informe del Expediente N00235-2017-JUS/CGP que, siendo que la exigibilidad de la ejecución completa de las penas impuestas al solicitante Alberto Fujimori Fujimori, a sus 79 años de edad y dada la condición de salud que muestra deterioro y vulnerabilidad, el citado solicitante no significaría un peligro para la sociedad y, por el contrario, dicha exigencia podría representar un daño irreparable a su derecho fundamental a la integridad física o, incluso, a su vida, por lo que debe primar el principio y derecho a la dignidad humana, sin que ello signifique una aceptación o validación de su accionar o una eliminación de la reprochabilidad moral y social de los delitos; en ese sentido, la citada Comisión recomienda la concesión del indulto y derecho de gracia por razones humanitarias; que hace que esta persona no está en capacidad de recibir sanción."

Dentro del marco de la Supervisión de Cumplimiento de la Sentencias de la Corte Interamericana de Derechos Humanos (en adelante, Corte IDH) en los casos Barrios Altos y la Cantuta vs. Perú, el Estado peruano informó de su decisión a la Corte IDH, lo que dio lugar a que esta se pronuncie el 30 de mayo de 2018 en los siguientes términos: "Disponer que tanto el Estado del Perú como (...) los representantes de las víctimas presenten a la Corte IDH, (...) información sobre los avances por parte de la jurisdicción constitucional del control del "indulto por razones humanitarias" concedido a Alberto Fujimori, en relación a la obligación de investigar, 
juzgar y, de ser del caso, sancionar las graves violaciones de derechos humanos determinadas en las sentencias de los casos de Barrios Altos y La Cantuta (...)."

Este pronunciamiento de la Corte IDH reavivó la discusión sobre la vigencia del indulto en un Estado constitucional de derecho. El caso del expresidente Alberto Fujimori no fue el único que generó argumentos jurídicos a favor y en contra del indulto: hubo otros casos que le antecedieron y que también fueron controvertidos. El caso de los "narco indultos", llamados así porque en diversas zonas del país fueron indultadas muchas personas sentenciadas por el delito de tráfico ilícito de drogas, fue uno de ellos. También fue el indulto que el expresidente Ollanta Humala concedió, un día antes de concluir su gobierno (27 de julio de 2015) a una persona condenada a ocho años de pena privativa de libertad efectiva por el delito de violencia contra la autoridad (caso mediático por la condena excesiva). En este último caso se valoraron diversos argumentos: la existencia de informes de profesionales que daban cuenta de que dicha persona podía reincorporarse satisfactoriamente al medio familiar y social, que ella había cumplido con trabajar en el centro penitenciario en la que estaba recluida, que la afectación producida era de "mínima lesividad" y que tenía una carga familiar que atender (más que un indulto, la fundamentación correspondía aquí a la evaluación judicial de un beneficio penitenciario).

Los problemas que plantea el indulto son de diversa naturaleza, pese a que se ha regulado su otorgamiento mediante un procedimiento previo y una comisión de evaluación. Con los casos mencionados, da la impresión de que no es posible superar la discrecionalidad para su otorgamiento y las irregularidades en su concesión.

Para el presente trabajo centraremos nuestro interés en el caso del indulto del expresidente Alberto Fujimori tomando en consideración la decisión de la Corte IDH a partir del planteamiento de los siguientes problemas: ¿La Corte IDH debía pronunciarse sin que se hayan agotado los recursos internos? Aun siendo necesario el pronunciamiento de la jurisdicción interna, ¿debía la Corte establecer criterios sobre el "indulto por razones humanitarias"? ¿Estos criterios no generan un sesgo para los tribunales nacionales?, ¿Un indulto por razones humanitarias afecta realmente el derecho de acceso a la justicia de las víctimas y sus familiares?, ¿Se concedió correctamente el indulto humanitario al expresidente Alberto Fujimori? ¿Correspondía aplicar el test de proporcionalidad?

\section{ARGUMENTOS DE LA RESOLUCIÓN DE LA CORTE IDH}

El 30 de mayo de 2018 a fin de supervisar el cumplimiento de su sentencia recaída en el caso Barrios Altos y La Cantuta vs. Perú, la Corte IDH resolvió disponer en el punto 4 de la parte resolutiva de dicha resolución relacionada con el indulto al expresidente Fujimori, que de alguna forma se 


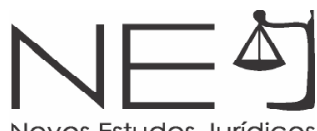

le informe lo que se resuelva en la justicia nacional. Esto implicaba, por un lado, reconocer la falta de agotamiento de los recursos internos, mientras que por otro lado, la exposición de una serie de argumentos sobre el fondo que, a nuestro modo de ver, significan un condicionante para la jurisdiccional nacional, a la que incluso la Corte IDH le recuerda la obligación de efectuar el control de convencionalidad.

Los argumentos a los que nos referimos son los siguientes:

La Constitución peruana vigente desde 1993 prevé la potestad del presidente de la república de conceder el indulto y el derecho de gracia (artículo $118.21^{\circ}$ ), este último para aquellos casos en los que la etapa de instrucción del proceso haya excedido el doble de su plazo más su ampliatoria. El Código Penal, por su parte, regula el indulto como una causa de extinción de la pena (artículos $85^{\circ}$ y $89^{\circ}$ ), y el otorgamiento del indulto está reglamentado por el Decreto Supremo № 008-2010-JUS.

El reglamento de concesión de indultos prevé tres supuestos de otorgamiento. El supuesto que se aplicó en el caso del expresidente Fujimori fue el literal b) del artículo 6.4, que señala: "Los que padecen enfermedades terminales graves, que se encuentren en etapa avanzada, progresiva, degenerativa e incurable; y además las condiciones carcelarias puedan colocar en grave riesgo su vida, salud e integridad."

En el fundamento 30 de esta decisión, la Corte señala "que la ejecución de la pena también forma parte de esta obligación y que durante la misma no se deben otorgar beneficios de forma indebida que puedan conducir a una forma de impunidad (...). Asimismo, la ejecución de sentencias es parte integrante del derecho al acceso a la justicia de las víctimas". Del mismo modo, refiriéndose a la resolución de cumplimiento que emitiera en el año 2012 en el caso Barrios Altos, la Corte resalta en el fundamento 31: "En atención a la regla de proporcionalidad, los Estados deben asegurar, en el ejercicio de su deber de persecución de esas graves violaciones, que las penas impuestas no se constituyan en factores de impunidad, tomando en cuenta varios aspectos como las características del delito y la participación y culpabilidad del acusado. Del mismo modo, el otorgamiento indebido de beneficios en la ejecución de pena puede eventualmente conducir a una forma de impunidad, particularmente cuando se trate de la comisión de graves violaciones a los derechos humanos, como las ocurridas en el presente caso. (...)"

Pese a que se espera la decisión de los tribunales nacionales, la Corte IDH considera necesario determinar sí el "indulto por razones humanitarias" es contrario al derecho internacional cuando es concedido a condenados por graves violaciones a los derechos humanos. Por ello, la Corte IDH señala que "el "indulto por razones humanitarias" otorgado por el Presidente de la República del Perú a Alberto Fujimori no (...) es una figura jurídica que extinga la acción penal o impida la investigación 
y juzgamiento, sino que implica una "extinción" de la pena que fue impuesta después de haberse efectuado el proceso penal en su contra. Sin embargo, se trata de una figura que permite que el Presidente de la República perdone una condena penal impuesta por los tribunales competentes del Poder Judicial para delitos de lesa humanidad, lo cual afecta el derecho de acceso a la justicia de las víctimas" (Fundamento 37).

Si bien la Corte acepta que no se ha pronunciado todavía en ningún caso sobre el indulto en particular (el indulto para casos de graves violaciones de derechos humanos sí ha sido tratado por el Tribunal Europeo de Derechos Humanos3; en los tribunales penales internacionales de la extinta Yugoslavia, Ruanda, Sierra Leona y Líbano sí se prevé que el mismo tribunal pueda aprobar el beneficio a los sentenciados con indultos o conmutaciones de la pena; y en el caso de la Corte Penal Internacional es posible que pueda aprobar la reducción de la pena y disponer la libertad anticipada cuando el sentenciado haya cumplido dos terceras partes de la condena o veinticinco años si fue condenado a cadena perpetua), sí ha señalado en su jurisprudencia el deber general del Estado de abstenerse de "recurrir a figuras que pretendan suprimir los efectos de una sentencia condenatoria"4 u "otorgar indebidamente beneficios en la ejecución de la pena", así como la importancia de "que la sentencia se cumpla en los términos en que fue decretada". ${ }^{5}$

La Corte considera una serie de instrumentos internacionales en los que se ha pronunciado para fundamentar la negativa de otorgar indultos en casos de delitos de lesa humanidad, como por ejemplo; las observaciones finales sobre Argelia en el año 2007 emitidas por el Comité Internacional de Derechos Humanos, así como también las observaciones finales del Comité contra la Tortura sobre informes relativos a Marruecos y Líbano (este mismo Comité se pronunció en el caso Kepa Urra Guridi Vs. España en el mismo sentido). Pero además, observó que algunos países de la Organización de Estados Americanos tienen expresamente establecido el impedimento de otorgar indultos a los sentenciados por delitos graves como los de lesa humanidad, como es el caso de Argentina, Colombia, Ecuador, Honduras, México, Nicaragua, Panamá, Paraguay, Uruguay y Venezuela; mientras que países como Bolivia, Perú, Chile y Brasil tienen restricciones de indulto y otras medidas para delitos graves. La tendencia en el Derecho Internacional de los Derechos Humanos y el Derecho

3 En lo que respecta al Tribunal Europeo de Derechos Humanos, en el caso Yeter Vs. Turquía, indicó que "cuando un agente estatal es acusado de crímenes que violen el Artículo 3, el procesamiento y juzgamiento penales no deben estar sujetos a prescripción y no debería permitirse el otorgamiento de una amnistía o indulto". El Tribunal Europeo sostuvo que la baja pena impuesta demostró una seria desproporción entre la gravedad de la ofensa y el castigo impuesto. Asimismo, en el caso Enukidze y Girgvliani Vs. Georgia, el referido tribunal indicó que "cuando un agente estatal, particularmente un agente encargado de hacer cumplir la ley, es condenado por un crimen que viola el artículo 2 de la Convención, el otorgamiento de una amnistía o indulto difícilmente puede servir el propósito de brindar un castigo adecuado" (Fundamento 39 de la resolución analizada).

4 Caso 19 Comerciantes Vs. Colombia. Fondo, Reparaciones y Costas. Sentencia de 5 de julio de 2004. Serie C No. 109, párr. 263. Ver también inter alia, Caso Molina Theissen Vs. Guatemala. Reparaciones y Costas. Sentencia de 3 de julio de 2004. Serie C No. 108, párr. 83; Caso de los Hermanos Gómez Paquiyauri Vs. Perú, supra nota 27, párr. 232; Caso Gómez Palomino Vs. Perú. Fondo, Reparaciones y Costas. Sentencia de 22 de noviembre de 2005. Serie C No. 136, párr. 140; Caso Huilca Tecse Vs. Perú. Fondo, Reparaciones y Costas. Sentencia de 3 de marzo de 2005. Serie C No. 121, párr. 108; Caso Masacre Plan de Sánchez Vs. Guatemala. Reparaciones. Sentencia de 19 de noviembre 2004 . Serie C No. 116, párr. 99; Caso Tibi Vs. Ecuador. Excepciones Preliminares, Fondo, Reparaciones y Costas. Sentencia de 7 de septiembre de 2004. Serie C No. 114, párr. 259.

$5 \quad$ Caso Rodríguez Vera y otros (Desaparecidos del Palacio de Justicia) Vs. Colombia, supra nota 65. 


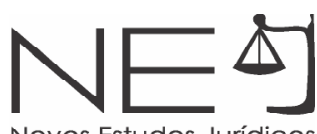

Penal Internacional es limitar que las condenas impuestas por violaciones graves a los derechos humanos "sean perdonadas o extinguidas por decisiones discrecionales de los poderes Ejecutivo o Legislativo" (fundamento 45).

Del razonamiento anterior se sigue que la Corte considera posible el "indulto humanitario", para lo cual debe realizarse una ponderación entre la obligación estatal de garantizar tanto la vida e integridad de las personas condenadas a una pena privativa de libertad como el derecho de acceso a la justicia y, en consecuencia, de las víctimas de graves violaciones a los derechos humanos y sus familiares.

Respecto a la obligación del Estado de garantizar la vida e integridad de las personas condenadas a una pena privativa de libertad, la Corte IDH ha establecido no solo su condición de "garante" de estas personas, sino también ha resaltado su deber de resguardar la salud y el bienestar $y$, en consecuencia, brindar condiciones que permitan vivir con dignidad. La Corte IDH cita el caso Chinchilla versus Guatemala para recordar los estándares fijados para las medidas que deben adoptar los estados cuando las personas privadas de la libertad tienen problemas de salud, más aún cuando se trate de enfermedades graves, crónicas o terminales; sin que dichas medidas supongan modificar la condena. La Corte IDH considera en este mismo sentido lo señalado por el Tribunal Europeo de Derechos Humanos que en el caso Mouisel, en el que indicó que si bien no se podría derivar de la Convención Europea que existe una obligación general para liberar a las personas privadas de libertad con base en motivos de salud, sí existe una obligación estatal de proteger el bienestar físico de las personas detenidas en centros penitenciarios, por ejemplo, mediante el otorgamiento de asistencia médica.

Por otro lado, está el derecho de acceso a la justicia de las víctimas de graves violaciones de los derechos humanos en relación a la ejecución de sentencia. La medida adoptada por el Estado peruano debió considerar una serie de factores o criterios como: que se haya cumplido una parte considerable de la pena privativa de libertad y se haya pagado la reparación civil impuesta en la condena; la conducta del condenado respecto al esclarecimiento de la verdad; el reconocimiento de la gravedad de los delitos perpetrados y su rehabilitación; y los efectos que su liberación anticipada tendría a nivel social y sobre las víctimas y sus familiares.

La Corte IDH considera que la ponderación debe ser realizada mediante un control judicial de dicho indulto en el ámbito nacional. 


\section{CUESTIONES QUE PLANTEA LA DECISIÓN DE LA CORTE IDH SOBRE EL INDULTO OTORGADO AL EXPRESIDENTE PERUANO ALBERTO FUJIMORI}

\subsection{CONTRADICCIÓN EN LA NECESIDAD DE AGOTAR LOS RECURSOS INTERNOS EN LA ETAPA DE SUPERVISIÓN DE CUMPLIMIENTO DE SENTENCIA DE LA CORTE}

Dentro del procedimiento seguido en razón del indulto otorgado a Alberto Fujimori, el Estado peruano planteó que debía agotarse los recursos internos ${ }^{6}$. Por su parte, los representantes de las víctimas y la Comisión plantearon que no era necesario el agotamiento cuando se trataba de supervisar el cumplimiento de sentencias expedidas por la Corte IDH, ya que con ello se ponía en riesgo de convertir en ilusorios sus fallos. Por otro lado, tanto los representantes de las víctimas como la Comisión consideran que no existía un recurso idóneo para cuestionar esta decisión, puesto que el amparo, en promedio, llevaría una media de seis años hasta llegar al Tribunal Constitucional como última instancia.

El Estado peruano informó a la Corte IDH sobre la falta de agotamiento de recursos internos; argumentando que el Tribunal Constitucional peruano ya advirtió que las gracias presidenciales puede ser sujetas a control constitucional, más aún que la Sala Penal Nacional, en otro caso sometido a juzgamiento (Caso Pativilca) donde estaría también comprendido el expresidente Fujimori, ha realizado control de convencionalidad y señalado que la resolución suprema que concedió el indulto no podría tener alcance sobre las causas en trámite porque "careció de motivación y denegó el derecho a las víctimas a ser oídas y no realizó ponderación entre lo solicitado por Alberto Fujimori y el derecho de las víctimas". Esta última decisión fue materia de impugnación.

Respecto a la impugnación, la Corte IDH considera que el cumplimiento de sus sentencias se encuentra en supervisión, y el requisito de agotamiento de los recursos internos no está contemplado por la Convención para la ejecución de sus decisiones; sin embargo, resolvió que debe realizarse el control constitucional del indulto, para aquel fin considera que el plazo que corresponde a los recursos de amparo o hábeas corpus que se deberían utilizar deberá computarse desde la fecha de notificación de la decisión de la Corte, con el fin de que las víctimas no se vean afectadas en su derecho de acceso a la justicia.

Es fundamental observar que existe una grave contradicción: la Corte IDH resolvió únicamente en base al derecho positivo, es decir, en el sentido de que el agotamiento de los recursos internos solo está previsto en el trámite inicial para evaluar la admisibilidad de una denuncia ante la Comisión

$6 \quad$ No se planteó como excepción preliminar puesto que como medio de defensa del Estado en la etapa preliminar ante la Comisión Interamericana, lo que buscaría es evitar que exista un procedimiento contencioso, que en este caso se dio y que concluyó con la sentencia de la Corte IDH en el caso Barrios Altos y La Cantuta vs. Perú. 


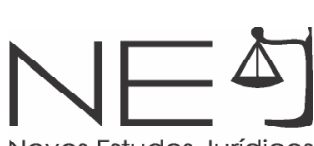

Interamericana de Derechos Humanos, sin observar qué principio subyace a dicha regla7, que es el carácter subsidiario o complementario de las jurisdicciones supranacionales. ${ }^{8}$

Comentando a Dworkin y su trabajo sobre las etapas interpretativas. Lifante refiriéndose precisamente a la etapa interpretativa propiamente dicha, señala: "(...) se pretende establecer una justificación general de los principales elementos que conforman la práctica identificada en la etapa anterior. Para realizar esta tarea es necesario determinar cuáles son los valores y objetivos que se considera que la práctica persigue (los principios que subyacen tras las reglas). Es precisamente esta justificación la que constituye, para Dworkin, el "sentido" o "significado" de la práctica."9

Teniendo en cuenta lo señalado, tiene sentido agotar primero los recursos internos antes de acudir a la Corte IDH, pues es el Estado al que le corresponde inicialmente resolver los asuntos que se presentan en el ámbito en el que ejerce soberanía. Sin embargo, es posible aplicar una excepción a esta regla solo si estos recursos no existen en el ámbito interno, si el Estado establece obstáculos o si este último no ofrece las garantías o la demora puede determinar un daño irremediable ${ }^{10}$.

Agotar los recursos internos no implicaría hacer inefectiva la decisión de la Corte, pues esta misma reconoce que el Tribunal Constitucional peruano ya había realizado el control jurisdiccional de indultos anteriormente con el argumento de que no existen zonas de control jurisdiccional cuando se trata de afectación de derechos fundamentales. Este último criterio ya había sido considerado por la Corte IDH en casos anteriores. ${ }^{11}$

7 “(...) Siendo así, existe sólo una única respuesta correcta que puede derivarse del sistema jurídico, y esto es así porque el sistema no incluye solo el derecho explícito reconocido como tal, sino un conjunto de principios fundamentales que son consistentes entre sí y también con respecto a las reglas explícitas." (BELTRAN, Miquel. La noción de interpretación de Dworkin. En Taula. Quaderns de Pensament N 6. Desembre de 1986. Universitat de les Illes Balears. p. 58).

8 "En el mismo preámbulo de la Convención Americana sobre Derechos Humanos se señala que la protección internacional de los derechos humanos es "coadyuvante o complementaria de la que ofrece el derecho interno de los Estados americanos"; esta noción ha sido reiterada y desarrollada por la Corte, al sostener que "la regla del previo agotamiento de los recursos internos permite al Estado resolver el problema según su derecho interno antes de verse enfrentado a un proceso internacional, lo cual es especialmente válido en la jurisdicción internacional de los derechos humanos, por ser ésta 'coadyuvante o complementaria' de la interna." (FAÚNDEZ LEDESMA, Héctor. El agotamiento de los recursos internos en el sistema americano de protección de los derechos humanos. En Revista IIDH, Volumen 46, 2007, p. 46). LIFANTE VIDAL, Isabel. "El derecho como práctica interpretativa". En El legado de Dworkin a la filosofía del derecho. Tomando en serio el imperio del erizo. CEPC, Madrid, 2015, p. 173.

10 CALETTI, Leandro; STAFFEN, Márcio Ricardo. O controle de convencionalidade pela via difusa como forma de otimização e exigibilidade dos direitos humanos. Revista da AGU. Brasília, v. 14, n. 04, out./dez. 2015, p. 133-156. Caso Yatama vs. Nicaragua, fundamento jurídico 175. 


\subsection{A PESAR DE SUGERIR QUE EL ASUNTO SEA RESUELTO POR LA JURISDICCIÓN INTERNA ¿LA CORTE IDH DEBÍA PRONUNCIARSE SOBRE EL FONDO Y DESAR- ROLLAR CRITERIOS PARA TOMARLOS EN CONSIDERACIÓN VÍA CONTROL DE CONVENCIONALIDAD?}

En los argumentos esgrimidos por la Corte IDH sobre el indulto humanitario encontramos algunas consideraciones sobre el fondo de la controversia (a los que denomina en el fundamento 64 "los estándares" que fueron expuestos desde el considerando 45 hasta el 58; además de los "serios cuestionamientos" relativos al cumplimento de los requisitos jurídicos del indulto estipulados en el derecho peruano expuestos en el considerado 58 al 69) que serían sugeridos de modo directo al tribunal nacional a efectos de efectuar, como señala en el fundamento 65 de la resolución analizada, el "control de convencionalidad"12.

En los estándares sobre el indulto, la Corte IDHG, establece lo siguiente:

Existe una tendencia creciente en el Derecho Internacional de los Derechos Humanos y en el Derecho Penal Internacional a limitar que las condenas impuestas sean perdonadas o extinguidas por decisiones discrecionales de los poderes ejecutivo o legislativo.

La aplicación de una figura jurídica como el "indulto por razones humanitarias" constituye un obstáculo para el cumplimiento de la obligación de investigar, juzgar y, de ser el caso, sancionar tales violaciones. Esto afecta el derecho de acceso a la justicia de las víctimas de graves violaciones y sus familiares en cuanto a lo que se refiere a la ejecución.

En atención a la regla de la proporcionalidad, los estados deben asegurar el ejercicio del deber de persecución de esas graves violaciones, y que las penas impuestas y su ejecución no se conviertan en factores de impunidad, tomando en cuenta las características del delito y la participación, así como la culpabilidad. Adicionalmente, el otorgamiento indebido de los beneficios puede conducir a una forma de impunidad.

El Estado debe adoptar medidas que aseguren la atención médica adecuada de los condenados que cumplan pena privativa de libertad, valorando inclusive, de ser necesario, medidas alternativas a dicha pena o que la modifiquen. Es posible que se adopten las medidas y facilidades para proteger la vida y la integridad del condenado, siempre que sean regulares y tengan un fin legítimo que no signifique únicamente dejar de asegurar la ejecución de la pena. En aquellos casos de violaciones de

12 "(...) el órgano judicial tiene la función de hacer prevalecer la Convención Americana y los fallos de esta Corte sobre la normatividad interna, interpretaciones y prácticas que obstruyan el cumplimiento de lo dispuesto en un determinado caso". (Caso Gelman vs. Uruguay. Supervisión de Cumplimiento de Sentencia. Resolución de la Corte Interamericana de Derechos Humanos del 20 de marzo de 2013 , fundamento jurídico 73). 


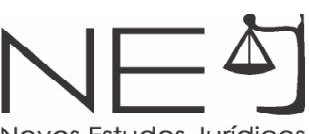

derechos humanos, dicha medida o figura debe ser la que menos restrinja el derecho de acceso a la justicia de las víctimas.

Si el Poder Ejecutivo tiene el poder de extinguir la pena mediante una decisión discrecional, es necesario que exista la posibilidad de solicitar el control jurisdiccional de esta última que permita realizar un análisis de ponderación respecto a la afectación que ocasione en los derechos de las víctimas y sus familiares.

En cuanto a los serios cuestionamientos para el otorgamiento del indulto, se establece lo siguiente:

La objetividad de la Junta Médica Penitenciaria que evalúo a Alberto Fujimori, en tanto uno de sus integrantes lo había atendido anteriormente en el Instituto de Enfermedades Neoplásicas.

Las diferencias sustanciales entre el acta de la Junta Médica Penitenciaria del 17 de diciembre de 2017 y la segunda "acta ampliatoria", suscrita dos días después.

Para el perdón de la pena en conductas como las atribuidas, la carga argumentativa deberá ser mayor. Sin embargo, ni en la Resolución Suprema N²81-2017-JUS ni en las actas médicas se explican cuál o cuáles son las enfermedades no terminales graves que se encuentran en etapa avanzada progresiva, degenerativa e incurable. Ante la Corte, el Estado señaló que la enfermedad más grave era la fibrilación auricular paroxística y ya no la enfermedad cancerígena, explicación que no se encuentra en la decisión que otorgó el indulto.

Ni la resolución suprema ni el informe de las condiciones carcelarias explican cómo tales condiciones pueden colocar en una situación de riesgo la vida, la salud y la integridad de Alberto Fujimori. Tampoco si encontrarse en una casa habitación podría implicar que cuente con la atención médica inmediata que reduzca el riesgo a su vida.

El contexto en el que se otorgó el indulto fue el de una crisis política generada en diciembre de 2017 al iniciarse un proceso de vacancia contra el entonces presidente de la república, Pedro Pablo Kuczynki Godard, por supuestos actos de corrupción, situación que dio lugar a que se inicie una investigación preliminar contra tres congresistas y un ministro de Estado. Esto implicaría que dicho indulto fue producto de una negociación política.

Al no existir un pronunciamiento de fondo sobre el "indulto humanitario" concedido al expresidente Alberto Fujimori y dejar que sea la jurisdicción constitucional nacional que se encargue de efectuar el control correspondiente, nos preguntamos: ¿Era válido que la Corte IDH señalará pautas para la decisión en este caso en particular? Considerando que estas pautas no 
fueron desarrolladas en un caso anterior, y que se había emitido una decisión "inhibitoria" (para que se resuelva en la jurisdicción interna)13: ¿Podía la Corte IDH señalaslas y recalcar la obligación de las autoridades nacionales de realizar el "control de convencionalidad", que no es otra cosa que seguir los estándares fijados?

Por otro lado, en la resolución analizada se observa apreciaciones sobre aspectos fácticos que deben ser evaluados en las instancias nacionales, subrayando la necesidad de que sean consideradas, como señala en su fundamento 58, a partir de una comprobación rigurosa, estricta y objetiva. Esto nos lleva necesariamente a una cuestión probatoria y que no se puede observar en cualquier tipo de proceso, ya que los procesos constitucionales en el Perú no están dotados de una etapa de actuación probatoria propiamente dicha.

Lo expuesto en el párrafo anterior genera necesariamente una interrogante: ¿La actuación de la Corte no implica una afectación en la independencia judicial? A partir de los estándares señalados se derivarían solo dos caminos que necesariamente debe adoptar la jurisdicción nacional14:

a) No es aceptable el indulto para casos de lesa humanidad si así lo contempla expresamente alguna norma interna, o

b) Es posible de modo excepcional, siempre que se someta al test de proporcionalidad. Y en este último supuesto estaría en conflicto, de acuerdo a la Corte, la vida e integridad del beneficiario del indulto y el derecho de acceso a la justicia (en ejecución) de las víctimas o sus familiares. Pero partiendo además, en este último caso, de verificar el otorgamiento debido del indulto humanitario, dados los cuestionamientos subrayados por la Corte.

Nuestra posición, es que existe una afectación a la independencia judicial (con un juicio anticipado para un caso concreto que se dispone seguir encubriéndose en un fallo inhibitorio) y que afecta también la soberanía del Estado, a la que este no renunció cuando ratificó tratados de derechos humanos o cuándo se sometió a la competencia contenciosa de una corte supranacional, lo que hizo el Estado solo fue entregar una cuota de poder para un control de sus compromisos asumidos dentro de un marco de principios y reglas, que los jueces no pueden trastocar o modular por cierto concepto de "justicia".

13 "En esta clase de resoluciones judiciales "diferentes", el tribunal no declara, constituye ni condena, sino que se circunscribe a emitir un pronunciamiento mediante el cual expresa "que está inhibido para decidir sobre la existencia del derecho material pretendido, de manera que no niega ni afirma que ese derecho existe". Se trata de aquellas decisiones que (oficiosamente o a pedido de parte) declaran que el tribunal se encuentra impedido de emitir una declaración, lo que no involucra obstáculo alguno para que ulteriormente, y salvadas que fueran, las deficiencias u omisiones correspondientes, se genere un nuevo proceso que ahora sí podrá pronunciarse sobre el mérito del asunto." (PEYRANO, Jorge. "Las resoluciones judiciales diferentes: anticipatorias, determinativas, docentes, exhortativas e inhibitorias". En Revista lus et Veritas $\mathrm{N}^{\circ}$ 45. Diciembre del 2012, p. 86).

14 "La independencia externa en la perspectiva funcional reclama la reserva de jurisdicción, como dispositivo orientado a la preservación del ámbito propio de ésta frente a posibles extralimitaciones, preferentemente del legislativo, aunque no sólo.» (ANDRÉS IBÁÑ̃EZ, Perfecto. Los Derechos Fundamentales de los Jueces. Arnaiz, 2012 - ijf.cjf.gob.mx, consultado el 30 de julio de 2018). 


\subsection{UN "INDULTO POR RAZONES HUMANITARIAS" IMPLICARÍA IMPUNIDAD}

Una de las familiares de las víctimas del caso La Cantuta, Carmen Rosa Amaro Cóndor, manifestó lo siguiente: "(...) significa un insulto a la memoria y dignidad de cada uno de (sus) padres, hijos, hermanos (...y) es impunidad."; por otro lado, los representantes de la víctimas sostuvieron "que se ordene al Estado remover todo obstáculo que impide una efectiva reparación consistente en el cumplimiento de las sentencias condenatorias nacionales, (...)" y "(...) la medidas concedidas a Alberto Fujimori son contrarias a la reparación dictada por el Tribunal, de investigar, juzgar y sancionar a los responsables por las violaciones de (ambos casos) y por tanto carecen de efectos jurídicos".

A lo anterior debe sumarse el argumento de la Comisión Interamericana de prohibir expresamente el indulto en aquellos delitos en donde medien graves violaciones a los derechos humanos, ya que esto implicaría una insatisfacción del "derecho a la justicia de la víctimas", lo que sería más reprochable o grave cuando se trate de crímenes de lesa humanidad. Para la Comisión, era necesario adoptar otras medidas diferentes del indulto, que implica el perdón de la pena, ya que era posible darle al expresidente Fujimori un trato humanitario y con la atención médica debida, de modo que no se afectara el derecho de las víctimas.

La impunidad sería un argumento utilizado por los representantes de las víctimas. Para la Comisión, de acuerdo con la Corte, no sería así, puesto que en los casos Barrios Altos y La Cantuta se realizó la investigación y juzgamiento de los presuntos responsables, lo que dio lugar a una sentencia condenatoria en la que el expresidente Fujimori fue condenado a veinticinco años de pena privativa de libertad. No se habría dado una situación de "impunidad" propiamente, ya que las conductas fueron sancionadas, encontrándose en ejecución las penas impuestas, y el beneficiado por el indulto había cumplido hasta el momento del otorgamiento de la gracia más de diez años en prisión.

Por otro pate, el argumento de la impunidad sí era válido para el caso Pativilca, que justamente dio lugar a que la Sala Nacional considerara que el indulto otorgado no alcanzaba a este proceso, tal como se puede apreciar en el extremo de la Resolución Suprema N²81-2017-JUS de otorgamiento del indulto humanitario al expresidente Alberto Fujimori,_en relación a que alcanza "a los procesos que a la fecha se encuentren vigentes", ya que no existía ninguna motivación, mientras que la situación de enfermedad no impide que un juzgamiento prosiga, con la garantía que el imputado ejerza su derecho de defensa. 
En este punto no estaríamos propiamente ante un indulto: se trataría más bien del derecho de gracia reconocido en el artículo 118.21 de la Constitución peruana como una potestad del presidente de la república de aplicar a los procesados en caso que en la etapa de instrucción haya excedido el doble del plazo más su ampliatoria. Se advierte que ya no se trata de una causa de extinción de la pena, sino de la acción penal, y que eventualmente puede ser concedida por razones humanitarias. Sin embargo, en la resolución suprema que otorgó el indulto al expresidente Fujimori debió hacerse la diferencia tanto en su fundamentación jurídica como fáctica. ${ }^{15}$

\subsection{EL "INDULTO HUMANITARIO" SIGNIFICÓ AFECTACIÓN AL DERECHO DE} ACCESO A LA JUSTICIA DE LAS VÍCTIMAS O SUS FAMILIARES

En el Perú el derecho fundamental de acceso a la justicia está comprendido dentro del derecho a una tutela procesal efectiva e implicaría: el libre acceso al órgano jurisdiccional, a probar, a defenderse, al contradictorio e igualdad sustancial en el proceso, a no ser desviado de la jurisdicción predeterminada ni sometido a procedimientos distintos de los previstos por la ley, a la obtención de una resolución fundada en derecho, a acceder a los medios impugnatorios regulados, a la imposibilidad de revivir procesos fenecidos, a la actuación adecuada y temporalmente oportuna de las resoluciones judiciales y a la observancia del principio de legalidad procesal penal (artículo $4^{\circ}$ del Código Procesal Constitucional).

Si observamos la ejecución oportuna y completa de las decisiones judiciales como parte del derecho de acceso a la justicia, veremos que, efectivamente, en el ámbito de los procesos civiles, comerciales o laborales donde la controversia se origina por una pretensión privada, será satisfecho el derecho cuando se logre la ejecución de la sentencia en los términos en las que fue dictada. Sin embargo, ese razonamiento, no es pertinente sobre aquellas controversias que corresponden al Estado (titular exclusivo del ius punendi), y donde la víctima es un sujeto sui generis, puesto que

15 Del mismo modo, es de señalarse que para el caso de la gracia presidencial, es claro que constituyen límites formales de esta, los requisitos exigidos de manera expresa en el artículo 118, inciso 21 de la Constitución, a saber: 1) Que se trate de procesados, no de condenados 2) Que la etapa de instrucción haya excedido el doble de su plazo más su ampliatoria. 3) Aparte de los requisitos ya mencionados, cabe señalar la necesidad de refrendo ministerial (artículo 120 de la Constitución). "En lo referente a los límites materiales de la gracia presidencial, es de señalarse que en tanto interviene en la política criminal del Estado tendrá como límites el respetar los fines constitucionalmente protegidos de las penas, a saber fines preventivo especiales (artículo 139, inciso 22 de la Constitución) y fines preventivo generales, derivados del artículo 44 de la Constitución y de la vertiente objetiva del derecho a la libertad y seguridad personales. (Cfr. Exp. №. 019-205-PI/TC). Asimismo, el derecho de gracia, en tanto implica interceder ante alguno o algunos de los procesados en lugar de otros, debe ser compatibilizado con el principio-derecho de igualdad. Así, será válida conforme al principio de igualdad la gracia concedida sobre la base de las especiales condiciones del procesado. En ese sentido, la gracia presidencial deberá ser concedida por motivos humanitarios, en aquellos casos en los que por la especial condición del procesado (por ejemplo, portador de una enfermedad grave e incurable en estado terminal) tornarían inútil una eventual condena, desde un punto de vista de prevención especial. Por el contrario, la concesión de la gracia presidencial en un caso en el que el que la situación del procesado no sea distinta a la de los demás procesados y no existan razones humanitarias para su concesión, será, además de atentatoria del principio de igualdad, vulneratoria de los fines preventivo generales de las penas constitucionalmente reconocidos, fomentando la impunidad en la persecución de conductas que atentan contra bienes constitucionalmente relevantes que es necesario proteger." (STC. $\mathrm{N}^{\circ}$ 04053-2007-HC/TC, fundamentos jurídicos 26 a 28). 


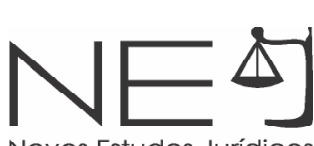

no le otorgan todos los derechos procesales ${ }^{16}$ en aras de que se conozca la verdad (en el sentido de hechos contrastado con los medios de prueba actuados en un debido juzgamiento), se evite la impunidad y se pretenda una reparación civil.

Corresponde seguidamente observar: ¿Qué implicancia tiene una condena? Puesto que las víctimas y sus familiares vieron satisfechas sus pretensiones de reparación cuando se expidió la condena a los responsables de las ejecuciones en los casos Barrios Altos y La Cantuta, o bien ¿la satisfacción solo sería completa con el "cumplimiento total de la condena"? Entonces, ¿la "justicia para las víctimas" sería considerado como el derecho a "un castigo que ellas consideren suficiente" en razón a su pérdida o sufrimiento?

La razón que subyace a la pena de acuerdo con la Constitución peruana ${ }^{17}$ y como regularmente se ha considerado en la mayor parte de legislaciones, es que cumpla con la prevención general y especial, no que satisfaga la "retribución al autor del hecho" para satisfacer a las víctimas y la sociedad, ya que no está legitimada la "venganza social ni particular" porque de ser así, el derecho penal no sería un instrumento del Estado para evitar que se cometan delitos y lograr que quiénes lo hicieron se resocialicen, sino más bien un instrumento de venganza. ${ }^{18}$

En un determinado momento en la ejecución de una sanción corresponde preguntarse dos cosas: ¿Se ha alcanzado el fin resocializador de la pena? ¿Es humanitario mantener privados de la libertad a personas que pueden no soportar la prisión, lo que no solo incluye a enfermos terminales, sino también a personas en especial estado de vulnerabilidad? Más allá del delito que se hubiera atribuido, ello ya no tendría que ver con las víctimas, sino con el Estado y las políticas que lleva adelante en relación a estos temas. En el Perú se han previsto diversas formas de extinción de la

16 Artículo $95^{\circ}$ del Código Procesal Penal del 2004: “Derechos del agraviado 1.El agraviado tendrá los siguientes derechos:

a) A ser informado de los resultados de la actuación en que haya intervenido, así como del resultado del procedimiento, aun cuando no haya intervenido en él, siempre que lo solicite;

b) A ser escuchado antes de cada decisión que implique la extinción o suspensión de la acción penal, siempre que lo solicite;

c) A recibir un trato digno y respetuoso por parte de las autoridades competentes, y a la protección de su integridad, incluyendo la de su familia. En los procesos por delitos contra la libertad sexual se preservará su identidad, bajo responsabilidad de quien conduzca la investigación o el proceso.

d) A impugnar el sobreseimiento y la sentencia absolutoria.

2. El agraviado será informado sobre sus derechos cuando interponga la denuncia, al declarar preventivamente o en su primera intervención en la causa.

3. Si el agraviado fuera menor o incapaz tendrá derecho a que durante las actuaciones en las que intervenga, sea acompañado por persona de su confianza."

17 El artículo $139^{\circ}$, inciso 22 de la Constitución, concordante con el artículo 10.3 del Pacto Internacional de Derechos Civiles y Políticos, establece lo siguiente: "El régimen penitenciario consistirá en un tratamiento cuya finalidad esencial será la reforma y la readaptación social de los penados".

18 "Desde Grozio, Hobbes, Locke, Puffendorf y Thomasius hasta Montequieu, Beccaria, Voltaire, Filangieri, Bentham y Pagano, todo el pensamiento penal reformador está de acuerdo en considerar que las aflicciones penales son precios necesarios para impedir daños mayores a los ciudadanos, y no constituyen homenajes gratuitos a la ética o a la religión o al sentimiento de venganza." (FERRAJOLI, Luigi. EI Derecho penal mínimo. En Prevención y teoría de la pena. Santiago de Chile: Editorial Jurídica Cono Sur Ltda., 1995. p. 33). 
sanción o de una libertad anticipada, como el otorgamiento de beneficios penitenciarios, la conversión de penas o la exención de la pena, todos ellos dependientes de la decisión judicial y previo debate entre la defensa y el Ministerio Público, que debe vigilar la legalidad. Sin embargo, el indulto y la conmutación de penas son reconocidas en la Constitución como una potestad del Poder Ejecutivo.

Esta potestad para considerar que no afecta la efectividad de una sanción o genere impunidad debería ejercerse con estricto cumplimiento de las condiciones o requisitos humanitarios y siempre que el sujeto haya cumplido una parte considerable de la condena impuesta, tal como sucede con los otros institutos que en ejecución penal permiten una libertad anticipada.

\section{5 ¿EL OTORGAMIENTO DEL INDULTO ES UNA POTESTAD DISCRECIONAL} EN EL PERÚ?

La Constitución política del Perú reconoce como una potestad del Poder Ejecutivo el otorgamiento del indulto (artículo $118.21^{\circ}$ ), mientras que la Corte Interamericana de Derechos Humanos hace mención en sus fundamentos que se trata de un poder discrecional. Si consideramos como discrecional aquello que no está reglado y sobre lo que existe libertad de decidir ${ }^{19}$, tomando la idea de discrecionalidad no como posibilidad de optar entre varias alternativas, sino de decidir sin que existan estándares jurídico aplicables ${ }^{20}$ o la ausencia de enjuiciabilidad ${ }^{21}$, entonces dicha calificación no correspondería a la realidad del indulto tal como está previsto en la actualidad en el Perú. Si bien es cierto, que antes el ejercicio del poder de indultar se ejercía con absoluta discrecionalidad y dependía totalmente de la voluntad del presidente de la república, justamente por el desarrollo del Estado constitucional y principalmente por las sentencias que sobre el indulto emitiera el Tribunal Constitucional peruano, dicha situación ha cambiado.

Actualmente existen estándares jurídicos, puesto que la decisión del indulto debe tener en consideración límites formales y materiales, así como una motivación. ${ }^{22}$ Además, su otorgamiento debe estar sujeto a una reglamentación donde se prevea las consideraciones para su concesión y un procedimiento, con la participación de órganos "técnicos", para calificar la situación particular que plantea cada pedido de indulto. Finalmente, el indulto puede ser sujeto a control jurisdiccional como se ha realizado en algunos casos a través del proceso de hábeas corpus.

19 "(...) resulta prácticamente unánime la idea de que la discrecionalidad es un cierto margen de libertad en la toma de decisiones. Sin embargo, y como no podía ser de otro modo, esta unanimidad empieza a desvanecerse a la hora de precisar algo más en qué consiste dicha libertad." (LIFANTE VIDAL, Isabel. Dos conceptos de discrecionalidad jurídica. En Doxa. Cuadernos de Filosofía del Derecho. Universidad de Alicante. 2002, p. 417).

20 "La discrecionalidad haría referencia, pues, a la adopción de decisiones de forma desvinculada del ordenamiento jurídico." (LIFANTE VIDAL, Isabel. Op. cit., p. 418).

21 "De esta opinión sería, por ejemplo, Dworkin (1989), para quien uno de los sentidos débiles que adopta el término discrecionalidad es precisamente aquél que hace referencia a que la decisión de alguien es definitiva, en el sentido de que ninguna autoridad superior puede revisarla y anularla, como la decisión del juez de línea de si un jugador está fuera de juego." (LIFANTE VIDAL, Isabel. Op. cit., p. 419). 22 "Ello no es sino consecuencia de la irradiación de la Constitución y su fuerza normativa en todo el ordenamiento jurídico. De este modo, para respetuoso de los derechos fundamentales, principios y valores constitucionales. Así, por ejemplo, resulta exigible un estándar mínimo de motivación que garantice que éste no se haya llevado a cabo con arbitrariedad." (STC N 03660-2010-HC/TC, fundamento jurídico 9). 


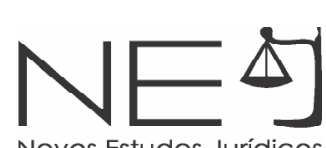

La motivación del indulto determina el límite entre un acto justificado y legítimo respecto de una arbitrariedad. ${ }^{23}$ La motivación determina la corrección: el que sea suficiente, coherente y aceptable determinará su carácter debido, que finalmente será algo que deberá evaluar un órgano judicial interno, dado que el control jurisdiccional ya fue realizado en casos anteriores. ${ }^{24}$

El reglamento peruano de concesión de indultos prevé tres supuestos de otorgamiento (Decreto Supremo N 008-2010-JUS). En el caso del expresidente Fujimori se aplicó el literal b) del artículo 6.4: "Los que padecen enfermedades terminales graves, que se encuentren en etapa avanzada, progresiva, degenerativa e incurable; y que además las condiciones carcelarias puedan colocar en grave riesgo su vida, salud e integridad."

De aquí que, se reconocen dos aspectos fundamentales para poder otorgar el indulto humanitario: 1. Que el beneficiario tenga una enfermedad terminal grave que se encuentre en etapa avanzada, progresiva, degenerativa e incurable, y 2. Que las condiciones carcelarias puedan colocar en grave riesgo su vida, salud e integridad. Sobre el primer presupuesto, da la impresión que la enfermedad debe reunir todas las condiciones descritas, es decir, debe tratarse de enfermedades "terminales graves, en etapa avanzada, progresiva, degenerativa e incurable". De la redacción se deriva que las condiciones deben ser concurrentes y no alternativas, y es aquí donde se aprecia que el derecho manifestado a través del lenguaje puede tener grandes problemas ${ }^{25}$ derivados, por ejemplo, de una incorrecta redacción o construcción gramatical.

En la Resolución Suprema N²81-2017-JUS que concede el "indulto humanitario" al expresidente Fujimori, se observa la exigencia de una serie de dolencias o enfermedades verificadas por una junta médica ${ }^{26}$, que además debe ser respaldado por un informe social. ${ }^{27}$ Sin embargo, en ambos documentos no se señala expresamente que se trate de una situación grave, avanzada, progresiva o degenerativa, siendo este uno de los aspectos que da lugar a los "cuestionamientos serios" que establece la Corte IDH sobre el otorgamiento del indulto.

$23 \quad$ Al respecto, el Tribunal Constitucional ha expresado: “(...) sin embargo, ello no obsta que pueda ser objeto excepcionalmente de anulación en sede jurisdiccional". Y agrega: "un indulto concedido bajo un error tan grave sobre el estado de salud torna en puramente aparente la motivación en la que se sustenta el mismo" (STC. № 03660-2010-HC/TC, fundamento jurídico 10).

24 STC. $\mathrm{N}^{\circ} 04053-2007-\mathrm{HC} / \mathrm{TC}$ y STC. $\mathrm{N}^{\circ} 03660-2010-\mathrm{HC} / \mathrm{TC}$.

25 "No sé si la lista de tipos de actos que se pueden hacer con las palabras es infinita, pero sí es enormemente más larga (...) cuando me pregunto cómo debo tomar la expresión de mi amigo o cuál es su fuerza, me estoy preguntando qué cosa, de las tantas que pueden hacerse con palabras, acaba de hacer mi interlocutor, la de decir lo que dijo, en las circunstancias y forma que lo dijo." (CARRIÓ, Genaro R. Notas sobre el derecho y lenguaje. Lexis Nexis, Abeledo Perrot, Quinta Edición, 2006, p. 18).

26 "el Acta de Junta Médica Penitenciaria, de fecha 17 de diciembre de 2017, ampliada con fecha 19 de diciembre de 2017, señala como diagnóstico del interno: fibrilación auricular paroxística con riesgo moderado de trombo embolismo, hipertensión arterial crónica con crisis hipertensivas a repetición que han merecido atención de emergencia y evacuación, cardiopatía hipertensiva de grado leve - moderado, insuficiencia mitral, hipotiroidismo sub clínico, cáncer de lengua tipo carcinoma epidermoide medianamente invasivo intervenido quirúrgicamente hasta en seis oportunidades con riesgo de recidiva, trastorno depresivo en tratamiento farmacológico, hipertrofia benigna prostática grado II, insuficiencia periférica vascular y hernia lumbar de núcleo pulposo L2 - L3; (...)"

27 "Que, asimismo, el Informe Social No 01-2017-INPE/18- 239-S.S., de fecha 04 de diciembre de 2017, indica que el interno se encuentra delicado de salud, con diagnóstico médico de un cáncer de alto riesgo en la cavidad bucal; asimismo, refiere que dicho estado le impide el desarrollo normal de sus actividades cotidianas, su dolencia le limita la fluidez de una pronunciación correcta. Refiere también que de modo continuo recae en un estado de postración por depresión de la que se recupera de forma momentánea, (...)" 
En cuanto al segundo supuesto, el de las condiciones carcelarias, también se observa un informe que da cuenta de que solo se tienen en el establecimiento de Barbadillo las condiciones básicas que no serían suficientes para el reguardo de la vida e integridad del beneficiado. ${ }^{28}$ Al respecto, considero que era necesario establecer la relación entre esas condiciones básicas y el estado de salud del beneficiario, justamente para poder apreciar que, efectivamente, partiendo de la imposibilidad del Estado para poder implementarlos, requería estar en un lugar diferente y con ciertas medidas especiales que eviten cualquier situación de peligro para su vida o salud.

Por lo señalado, no es que dicha decisión careció de motivación: tal vez, que lo que se podría poner en tela de juicio es la verdad o falsedad de los aspectos fácticos o el grado de credibilidad o fiabilidad de los expertos o técnicos que hicieron los informes, lo cual conllevaría un proceso judicial donde se pueda actuar pruebas o cuestionar las pruebas existentes. ${ }^{29}$ Pero también podríamos estar ante una "motivación hipócrita", esto es, manifestar argumentos que oculten las "verdaderas" razones. ${ }^{30}$

Justamente se refuerza la idea de una "motivación hipócrita", cuando se observa el contexto en el que esta decisión se tomó, puesto que en oportunidades anteriores el presidente de la república tocó el tema, pero sin darle mayor importancia. Sin embargo, cuando el mandatario estuvo inmerso en una crisis política en la que se intentaba su vacancia y en el ámbito parlamentario era necesario tener el voto suficiente de congresistas, para evitarlo, se advirtió que el indulto tenía visos de una negociación.

En este punto convendría recordar el artículo desarrollado por González Lagier sobre Buenas razones, malas intenciones, en aquella parte en la que refiriéndose a la razonabilidad mínima de los actos, se advierte que se presenta cuando se cree actuar por buenas razones que objetivamente no lo eran en la ocasión concreta en al que se actuó, por falta de deliberación, urgencia al actuar, por una defectuosa interpretación de las circunstancias, entre otros factores que describe el autor citado ${ }^{31}$; pero que podrían aplicarse en el análisis de la decisión de este indulto en particular.

28 "(...) de fecha 12 de diciembre de 2017, este cuenta con los servicios básicos; sin embargo, por la edad avanzada del interno y las diversas dolencias que presenta, las condiciones del establecimiento penitenciario no cuenta con los servicios necesarios para la atención médica, por lo que en reiteradas oportunidades debe ser evacuado a un centro de salud (...)"

29 Cabe observar que no plantea la decisión ante la Corte IDH "cuestiones de prueba", en el sentido de si corresponde o no a este sede supranacional determinar si los hechos o situación invocada en el indulto estuvo probada o no, las cuestiones probatorias tendrían que ser discutidas en sede nacional dentro de un proceso que permita actividad probatoria, puesto que como indica ATIENZA: "(...) las dificultades pueden concernir a la fiabilidad de los diversos medios de prueba: testigos, documentos, informes periciales, indicios (...) El Juez con el Derecho Probatorio tiene que combinar el manejo racional de la prueba de la inducción con el Derecho Probatorio que forma parte de su sistema jurídico. Y ese Derecho puede contener normas que prohíban el uso de ciertos medios de prueba, que requieran un estándar de prueba más o menos exigente (según las materias), que establezcan ciertos criterios sobre cómo interrogar testigos, etcétera." (ATIENZA, Manuel. Curso de Argumentación Jurídica. Madrid. Editorial Trota. 2018, p. 434).

30 ATIENZA, Manuel. Op. cit. p. 147.

31 GONZALES LAGIER, Daniel. Buenas razones, malas intenciones. En Doxa: Cuadernos de Filosofía del Derecho № 16, 2003 , p. 669. 


\subsection{LA APLICACIÓN DEL TEST DE PROPORCIONALIDAD SOBRE “EL INDUL-}

TO HUMANITARIO"

Si bien la Corte IDH no considera que el indulto sea motivo de seguimiento para la ejecución de sus decisiones, indica que deberá ejercerse un control jurisdiccional interno sobre él, al que sugiere aplicar el test de proporcionalidad en el sentido de observar que por razones humanitarias tiene un fin legítimo: resguardar el derecho a la vida e integridad de una persona condenada penalmente, fin que entraría en conflicto con el derecho de acceso a la justicia de las víctimas y sus familiares de hechos que implicaron graves violaciones a los derechos humanos. ${ }^{32}$

Por un lado, consideramos que no existe el conflicto señalado por la Corte IDH, puesto que desde nuestro punto de vista, el derecho de las víctimas y familiares fue satisfecho con la investigación, identificación de los responsables y su condena. Más bien lo que estaría en juego sería que en ejecución de una sentencia penal el fin resocializador y preventivo se haya cumplido, y se muestre la efectividad punitiva que en todo caso sería el interés afectado por el indulto. Más que un derecho, se habría afectado una norma fin. ${ }^{33}$

Ingresar a ese ámbito involucraría una ponderación con una excesiva discrecionalidad, pues como explica Atienza: "(...) "Si se trata de directrices, el problema que se les suele plantear a los jueces - como se ha dicho - es controlar si la ponderación (concreción de objetivos) llevada a cabo por los legisladores o por la Administración es correcta, si se ha efectuado sin vulnerar determinados límites. Sería discutible si en algún caso está justificado que los jueces creen reglas a partir simplemente de directrices, eso es, que lleven a cabo una "ponderación discrecional"."34

Por otro lado, siguiendo la línea de realizar el test de proporcionalidad, nos preguntamos: ¿Es posible que por la vía interpretativa se establezca una restricción al indulto como causa de extinción de la pena en delitos como los de lesa humanidad? El legislador no lo hizo en su debida oportunidad. Es más, ni siquiera fue materia de un proyecto o debate en el legislativo.

32 "La técnica de la ponderación tiene una gran presencia en numerosos tribunales latinoamericanos —especialmente, en cortes supremas y tribunales constitucionales-, lo que en buena medida ha sido una consecuencia de la recepción de las ideas al respecto de Robert Alexy que, a su vez, pueden considerarse como una racionalización del manejo por parte de los tribunales constitucionales europeos del principio de proporcionalidad. Alexy concibe los derechos constitucionales como principios, y los principios como mandatos de optimización, que ordenan que algo debe realizarse en la mayor medida posible (de acuerdo con las posibilidades fácticas y normativas existentes). Cuando se producen conflictos entre derechos (o entre principios; lo cual tiene lugar en todos los campos del Derecho) los mismos deben resolverse aplicando un test de proporcionalidad, o sea, aplicando el principio de proporcionalidad que, para Alexy, viene a ser una especie de meta-principio o, si se quiere, el principio último del ordenamiento jurídico." (ATIENZA, Manuel. A vueltas con la ponderación. En Anales de la cátedra Francisco Suárez. Revista de filosofía jurídica y política. Volumen 44, 2010, p. 46).

33 "(...) supone dos formas distintas de regular la conducta. En un caso (las normas de acción), si se dan ciertas condiciones, entonces alguien debe, no debe o puede hacer algo. En el otro (normas de fin) se señalan ciertos fines a alcanzar y se deja que el destinatario elija (dentro de los límites fijados por otras normas) los medios adecuados para ello." (ATIENZA, Manuel. El sentido del derecho, 2da. edición, Ariel, Barcelona, 2003, pp. $79-80)$ 
De incorporarse dicha restricción por la vía interpretativa, no solo se afectaría la legalidad penal ${ }^{35}$, sino que se estaría dando una interpretación que aunque fuera constitucional, implicaría una aplicación retroactiva y desfavorable para el condenado indultado. ${ }^{36}$

\section{PROPUESTAS DE SOLUCIÓN DEL PROBLEMA}

Ejercer el control jurisdiccional en el ámbito nacional sobre el indulto humanitario otorgado al expresidente Alberto Fujimori observando si dentro del marco jurídico nacional se otorgó dicho beneficio cumpliendo con los presupuestos establecidos en el reglamento vigente, las sentencias del Tribunal Constitucional en la materia (fijaron estándares jurídicos) y observando que se realice una debida motivación.

Revisión del indulto respecto a su regulación actual en aras de establecer mayores precisiones y garantías para su otorgamiento o en una reforma constitucional para eliminar dicha potestad del Ejecutivo, considerando la existencia de otros medios judiciales de obtener una libertad anticipada.

Es necesario que la Corte IDH se autolímite en sus facultades, puesto que en aras de conseguir que sus fallos tengan efectividad así como los compromisos adoptados en los tratados. La Corte no debe asumir un rol activista que lejos de fortalecer el sistema americano de protección desincentiva la participación de los estados y pone en duda su imparcialidad.

\section{A MANERA DE CONCLUSIÓN}

Los fines del indulto no son discutibles, puesto que se sustentan en la compasión que se deriva del principio de humanidad para la aplicación de las penas, así como el reconocimiento de la dignidad que alcanza a todo ser humano, aun cuando estuviera condenado por delitos tan graves como los de lesa humanidad. Como en algún momento alegó el Estado peruano, no se puede convertir la pena privativa de libertad en "una pena de muerte encubierta".

35 Solo se contempló la restricción del indulto para casos de violación sexual de menores de edad, en el primer párrafo del artículo $3^{\circ}$ de la Ley $\mathrm{N}^{\circ} 28704$, que fuera objeto de una sentencia del Tribunal Constitucional de fecha 11 de noviembre de 2011, donde se establece: "(...) la eliminación de la posibilidad de indulto, de conmutación de pena, de gracia, y de concesión de los beneficios penitenciarios de redención de la pena por el trabajo y la educación, de semi-libertad y de liberación condicional, es representativa de la voluntad del legislador de que en los casos de condenas por los delitos de violación de menores de edad, el quantum de la pena impuesta se ejecute en su totalidad. (...) Ello tiene por finalidad, en primer término, optimizar el fin preventivo general de las penas en su vertiente negativa, es decir, optimizar el efecto desmotivador que la amenaza de la imposición y ejecución de una pena severa genera en la sociedad, protegiendo preventivamente el bien tutelado por el Derecho penal, en este caso, la integridad personal y el libre desarrollo de la personalidad de los menores de edad. Se asume que mientras de mayor peso axiológico sea el bien protegido al tipificarse la conducta, mayor deberá ser la pena que se amenaza imponer, generando así el Derecho penal una acción más disuasoria." (STC. N 00012-2010-PI/TC, fundamentos jurídicas 16 y 17).

$36 \quad$ “....) el fundamento de la prohibición de la retroactividad de los delitos y de las penas se encuentra - por encima de cualquier otra consideración - en la idea de seguridad jurídica. Razonamiento de diferente índole no son más que un desarrollo consecuente de este pensamiento; y así, desde un punto de vista de técnica jurídica cabe admitir que si la norma penal (presupuesto y consecuencia) desempeña una función de determinación o motivación, resulta una consecuencia lógica el que la ley preceda el comportamiento regulado." (RUíZ ANTÓN, Felipe. El principio de irretroactividad de la Ley Penal en la doctrina y jurisprudencia. Ponencia presentada en las Primeras Jornadas de Protección Judicial de los Derechos Fundamentales y Libertades Pública. Cáceres, 1989, p. 152). 
Sin embargo, cuando se ha dispuesto que el indulto no puede ser otorgado, y la restricción ha sido previa e inequívocamente establecida en la Ley, como en su momento sucedió con los delitos de violación sexual, el legislador ya realizó una ponderación que los jueces no pueden, vía una sentencia, modificar o cambiar su sentido.

La verificación de las condiciones de otorgamiento del "indulto humanitario" son fundamentales y debe realizarse de modo estricto justamente para que cumpla con su finalidad dentro del marco de la corrección y la compasión (fin humanitario).

Lo que se ha demostrado con esta decisión es que la Corte IDH debe autolimitarse dentro del marco del poder que los estados le otorgaron. Si una petición resulta improcedente, puesto que el Estado debe resolver el asunto en las instancias nacionales, este no debe dar lugar a que la Corte interfiera en la independencia judicial con criterios sobre el fondo de la controversia, más aún si fueron dados para el caso concreto.

La figura del indulto para evitar la manipulación política (posibles negociaciones) debe desaparecer, más aún en estos tiempos en los que un condenado puede lograr su libertad anticipada a través de mecanismos judicializados que garantizan un contradictorio, actuación de prueba, impugnación e imparcialidad judicial.

\section{REFERENCIA}

Caso Rodríguez Vera y otros (Desaparecidos del Palacio de Justicia) Vs. Colombia, supra nota 65.

ANDRÉS IBÁÑEZ, Perfecto. Los Derechos Fundamentales de los Jueces. Arnaiz, 2012 - ijf.cjf.gob.mx, consultado el 30 de julio de 2018.

ATIENZA, Manuel. A vueltas con la ponderación. En Anales de la cátedra Francisco Suárez. Revista de filosofía jurídica y política. Volumen 44, 2010, p. 46).

ATIENZA, Manuel. Curso de Argumentación Jurídica. Madrid. Editorial Trota. 2018, p. 434.

ATIENZA, Manuel. El sentido del derecho, 2da. Edición, Ariel, Barcelona, 2003, pp. 79 - 80.

BELTRAN, Miquel. La noción de interpretación de Dworkin. En Taula. Quaderns de Pensament N 6. Desembre de 1986. Universitat de les Illes Balears. p. 58.

CALETTI, Leandro; STAFFEN, Márcio Ricardo. O controle de convencionalidade pela via difusa como forma de otimização e exigibilidade dos direitos humanos. Revista da AGU. Brasília, v. 14, n. 04, out./dez. 2015, p. 133-156.

CARRIÓ, Genaro R. Notas sobre el derecho y lenguaje. Lexis Nexis, Abeledo Perrot, Quinta Edición, 2006, p. 18.

Caso 19 Comerciantes Vs. Colombia. Fondo, Reparaciones y Costas. Sentencia de 5 de julio de 2004. Serie C No. 109, párr. 263.

Caso de los Hermanos Gómez Paquiyauri Vs. Perú, supra nota 27, párr. 232; 
Caso Gelman vs. Uruguay. Supervisión de Cumplimiento de Sentencia. Resolución de la Corte Interamericana de Derechos Humanos del 20 de marzo de 2013, fundamento jurídico 73.

Caso Gómez Palomino Vs. Perú. Fondo, Reparaciones y Costas. Sentencia de 22 de noviembre de 2005. Serie C No. 136, párr. 140;

Caso Huilca Tecse Vs. Perú. Fondo, Reparaciones y Costas. Sentencia de 3 de marzo de 2005. Serie C No. 121, párr. 108;

Caso Masacre Plan de Sánchez Vs. Guatemala. Reparaciones. Sentencia de 19 de noviembre 2004. Serie C No. 116, párr. 99;

Caso Molina Theissen Vs. Guatemala. Reparaciones y Costas. Sentencia de 3 de julio de 2004. Serie C No. 108, párr. 83;

Caso Tibi Vs. Ecuador. Excepciones Preliminares, Fondo, Reparaciones y Costas. Sentencia de 7 de septiembre de 2004. Serie C No. 114, párr. 259.

FAÚNDEZ LEDESMA, Héctor. El agotamiento de los recursos internos en el sistema americano de protección de los derechos humanos. En Revista IIDH, Volumen 46, 2007, p. 46.

FERRAJOLI, Luigi. El Derecho penal mínimo. En Prevención y teoría de la pena. Santiago de Chile: Editorial Jurídica Cono Sur Ltda., 1995. p. 33.

GONZALES LAGIER, Daniel. Buenas razones, malas intenciones. En Doxa: Cuadernos de Filosofía del Derecho N 16, 2003, p. 669.

LIFANTE VIDAL, Isabel. Dos conceptos de discrecionalidad jurídica. En Doxa. Cuadernos de Filosofía del Derecho. Universidad de Alicante. 2002, p. 417.

LIFANTE VIDAL, Isabel. "El derecho como práctica interpretativa". En El legado de Dworkin a la filosofía del derecho. Tomando en serio el imperio del erizo. CEPC, Madrid, 2015, p. 173.

PEYRANO, Jorge. "Las resoluciones judiciales diferentes: anticipatorias, determinativas, docentes, exhortativas e inhibitorias". En Revista lus et Veritas N²4. Diciembre del 2012, p. 86.

RUÍZ ANTÓN, Felipe. El principio de irretroactividad de la Ley Penal en la doctrina y jurisprudencia. Ponencia presentada en las Primeras Jornadas de Protección Judicial de los Derechos Fundamentales y Libertades Pública. Cáceres, 1989, p. 152.

\section{RECEBIDO EM: 03/09/2019}

\section{APROVADO EM: 14/11/2019}

